\title{
Physical activity as a mediator of the impact of chronic conditions on quality of life in older adults Richard Sawatzky*1, Teresa Liu-Ambrose ${ }^{2}$, William C Miller ${ }^{3,4}$ and Carlo A Marra 5,6
}

Address: ${ }^{1}$ Nursing Department, Trinity Western University, 7600 Langley, British Columbia, V2Y 1Y1, Canada, ${ }^{2}$ Department of Physical Therapy, University of British Columbia, T325 2211 Wesbrook Mall, Vancouver, British Columbia, V6T 2B5, Canada, ${ }^{3}$ Department of Occupational Science and Occupational Therapy, University of British Columbia, T325 2211 Wesbrook Mall, Vancouver, British Columbia, V6T 2B5, Canada, ${ }^{4}$ GF Strong Rehabilitation Research Laboratory, University of British Columbia, T325 2211 Wesbrook Mall, Vancouver, British Columbia, V6T 2B5, Canada, ${ }^{5}$ Faculty of Pharmaceutical Sciences, University of British Columbia, 2146 East Mall, Vancouver, British Columbia, V6T 1Z3, Canada and ${ }^{6}$ Centre for Health Evaluation and Outcomes Sciences, Providence Health Care, St Paul's Hospital, 620B 1081 Burrard Street, Vancouver, B.C., V6Z 1Y6, Canada

Email: Richard Sawatzky* - rick.sawatzky@twu.ca; Teresa Liu-Ambrose - dtambrose@shaw.ca; William C Miller - bill.miller@ubc.ca; Carlo A Marra - carlo.marra@ubc.ca

* Corresponding author

Published: 19 December 2007

Health and Quality of Life Outcomes 2007, 5:68 doi:10.1 186/1477-7525-5-68

Received: 29 September 2007

Accepted: 19 December 2007

This article is available from: http://www.hqlo.com/content/5/I/68

(C) 2007 Sawatzky et al; licensee BioMed Central Ltd.

This is an Open Access article distributed under the terms of the Creative Commons Attribution License (http://creativecommons.org/licenses/by/2.0), which permits unrestricted use, distribution, and reproduction in any medium, provided the original work is properly cited.

\begin{abstract}
Background: Chronic conditions could negatively affect the quality of life of older adults. This may be partially due to a relative lack of physical activity. We examined whether physical activity mediates the relationship between different chronic conditions and several health outcomes that are important to the quality of life of older adults.

Methods: The data were taken from the Canadian Community Health Survey (cycle I.I), a cross-section survey completed in 200I. Only respondents who were 65 years or older were included in our study $(N=22,432)$. The Health Utilities Index Mark 3 (HUI3) was used to measure overall quality of life, and to measure selected health outcomes (dexterity, mobility, pain, cognition, and emotional wellbeing) that are considered to be of importance to the quality of life of older adults. Leisure-time physical activity was assessed by determining weekly energy expenditure (Kcal per week) based on the metabolic equivalents of self-reported leisure activities. Linear and logistic regression models were used to determine the mediating effect of leisure-time physical activity while controlling for demographic variables (age and sex), substance use (tobacco use and alcohol consumption), and obesity.
\end{abstract}

Results: Having a chronic condition was associated with a relative decrease in health utility scores and a relative increase in mobility limitations, dexterity problems, pain, emotional problems (i.e., decreased happiness), and cognitive limitations. These negative consequences could be partially attributed to a relative lack of physical activity in older adults with a chronic condition (14\% mediation for the HUI3 score). The corresponding degree of mediation was $18 \%$ for mobility limitations, $5 \%$ for pain, and 13\% for emotional wellbeing (statistically significant mediation was not observed for the other health attributes). These values varied with respect to the different chronic conditions examined in our study.

Conclusion: Older adults with chronic conditions are less likely to engage in leisure-time physical activities of at least $\mathrm{I}, 000 \mathrm{Kcal}$ per week, and this association partially accounts for some negative consequences of chronic conditions, including mobility limitations, pain, and emotional problems. These findings provide support for health promotion programs that facilitate or encourage increased leisure-time physical activity in older people with chronic conditions. 


\section{Background}

A chronic condition can be defined as a medical condition that is slow in its progress and long in its continuance. More than $80 \%$ of Canadians aged 65 and older report having at least one chronic condition [1]. Chronic conditions contribute to disability via physical impairments and functional limitations and consequently diminish quality of life in older adults. In older adults, chronic conditions have been associated with an increased risk for a variety of secondary health issues including medical conditions, such as disuse osteoporosis concomitant to sustaining a stroke, and psychosocial challenges, such as those related to depression and pain [2-4]. Chronic conditions also increase the costs of health care and long-term care [5]. Thus, the increased prevalence of chronic conditions in the aging population poses a significant challenge to society and the health care system.

Physical activity is a proven but remarkably underused health promotion modality [6]. Evidence has shown that regular physical activity contributes to healthy aging by preventing disability, morbidity, and mortality in older adults [7]. It has been demonstrated that physical activity decreases the likelihood of dying with disability almost two-fold when comparing those most physically active to those who were sedentary [8]. A graded, inverse relationship between total physical activity and mortality has been identified [9]. Regular physical activity can modify the severity or the progression of chronic conditions, thereby reducing both morbidity and mortality associated with chronic conditions [7]. Physical activity has various psychological and social benefits. For example, studies have shown that exercise alleviates depression [10], and provides additional therapeutic benefits beyond those resulting from psychotherapy [11] and the use of psychotropic medications [12,13]. Despite its many benefits, physical activity participation declines progressively with age [14], particularly among older adults who have chronic conditions.

Studies have demonstrated that physical activity can improve quality of life in adults with chronic conditions $[15,16]$. These associations have typically been examined with respect to a particular chronic condition, such as arthritis. However, it is unclear to what degree the negative impact of chronic conditions on quality of life and important health outcomes in older adults can be attributed to a lack of physical activity. It is also unclear whether this hypothesized mediating effect of physical activity is consistent with respect to different chronic conditions. This information is vital to understanding the role of physical activity in promoting quality of life in older adults.
The analytical objectives for this study are to: 1) examine the degree to which the negative impact of chronic conditions on quality of life and various important health outcomes (e.g., emotional problems, mobility limitations, pain, emotional wellbeing, and cognitive limitations) in older adults could be attributed to a lack of physical activity; and 2) examine whether the hypothesized mediating effect of physical activity is consistent with respect to some of the most prevalent chronic conditions in older adults (including musculoskeletal disorders, cardiovascular disorders, respiratory disorders, diabetes, urinary or bowel disorders, and strokes). We specifically hypothesized that those older adults who have a chronic condition but who maintained the recommended amount of physically activity of 1,000 Kcal per week would experience better health outcomes than those who are physically inactive.

\section{Methods}

The data were obtained from the Canadian Community Health Survey (CCHS) cycle 1.1 (Statistics Canada): a multi-cycle cross-sectional health survey of the Canadian population that contains information about chronic conditions, various health outcomes, health resource utilization, socio-demographics, and physical activity [17]. The sampling strategy included a stratified cluster design (83\% of total sample) to obtain proportional geographic and socio-economic representation of dwelling units across the 136 health regions in Canada. This sampling strategy was supplemented with a random digit dialing approach ( $10 \%$ of total sample) and a list frame of telephone numbers ( $7 \%$ of the total sample). This resulted in a total sample of 130,880 respondents who were all contacted by telephone to complete the survey. The national nonresponse rate was estimated at $20.0 \%$ [17]. People living in Indian Reserves, the Canadian Forces Bases, some remote areas, and people who did not dwell in a household as defined by Statistics Canada were not included. For this study, we utilized the data from respondents aged 65 years and older $(N=24,281)$.

The data were collected by Statistics Canada under the authority of the Statistics Act. Access to the data was granted by Statistics Canada based on a peer-reviewed proposal for this study. The researchers did not have access to any identifying information so that anonymity of the respondents was protected. The opinions expressed here do not represent the views of Statistics Canada.

\section{Classification of chronic conditions}

The respondents were asked to indicate whether they had a disease or another health condition diagnosed by a health professional that had lasted, or was expected to last, 6 months or more. These data were used to classify the older adults into the following overlapping groups based on those chronic conditions that are similar with 
respect to the predominant body systems involved: 1) respiratory disorders (asthma, chronic bronchitis, emphysema or chronic obstructive pulmonary disease), 2) musculoskeletal disorders (arthritis, fibromyalgia or back problems), 3) cardiovascular disorders (high blood pressure or heart disease), 4) diabetes, 5) urinary or bowel problems (urinary incontinence, Crohn's disease or colitis), and 6) those who were "suffering the effects of a stroke". Older adults with cancer, Alzheimer's disease or another form of dementia, Parkinson's disease, or multiple sclerosis were also included in our analyses. However, older adults who did not have any of the above chronic conditions but who did report having another chronic condition were not included $(n=1,809)$. Some chronic conditions, such as food or other allergies, cataracts, glaucoma, and thyroid conditions were not considered because their impact on quality of life, as measured by the Health Utilities Index [18], has previously shown to be indiscernible or mild in older adults [19]. Migraine headaches and epilepsy were not considered because their sporadic nature did not lend itself well to a cross-sectional analysis. We first compared the older adults who had one or more of the selected chronic conditions $(n=19,475)$ to those who reported having no chronic condition ( $n=$ $2,957)$, and we subsequently repeated these analyses for each of the above chronic condition groups (see Figure 1; the corresponding sample sizes for the chronic condition groups after listwise deletion are shown in Table 1).

\section{Dependent variables}

The dependent variables of interest were various health outcomes that are generally considered to be of importance to quality of life. The Health Utility Index Mark 3 (HUI3) $[18,20,21]$ was used in the CCHS for the measurement of these health outcomes. This instrument consists of 31 questions pertaining to eight health attributes that represent limitations associated with hearing, vision, speech, cognition, mobility, dexterity, pain, and emotional wellbeing (happiness). Utility weights for several health states were derived from the preferences obtained from a community sample of 504 adults in the city of Hamilton, Ontario, Canada [22]. Multi-attribute theory was used to calculate a total health utility score that can range from - 0.36 ("most disabled") to 1.00 ("perfect health") [22].

The HUI3 was also used to examine the impact of chronic conditions and physical activity on several distinct health attributes (including cognition, mobility, dexterity, pain and emotional wellbeing). The guidelines provided by the instrument developers were followed to concatenate the HUI3 questions to obtain ordinal summary scores for

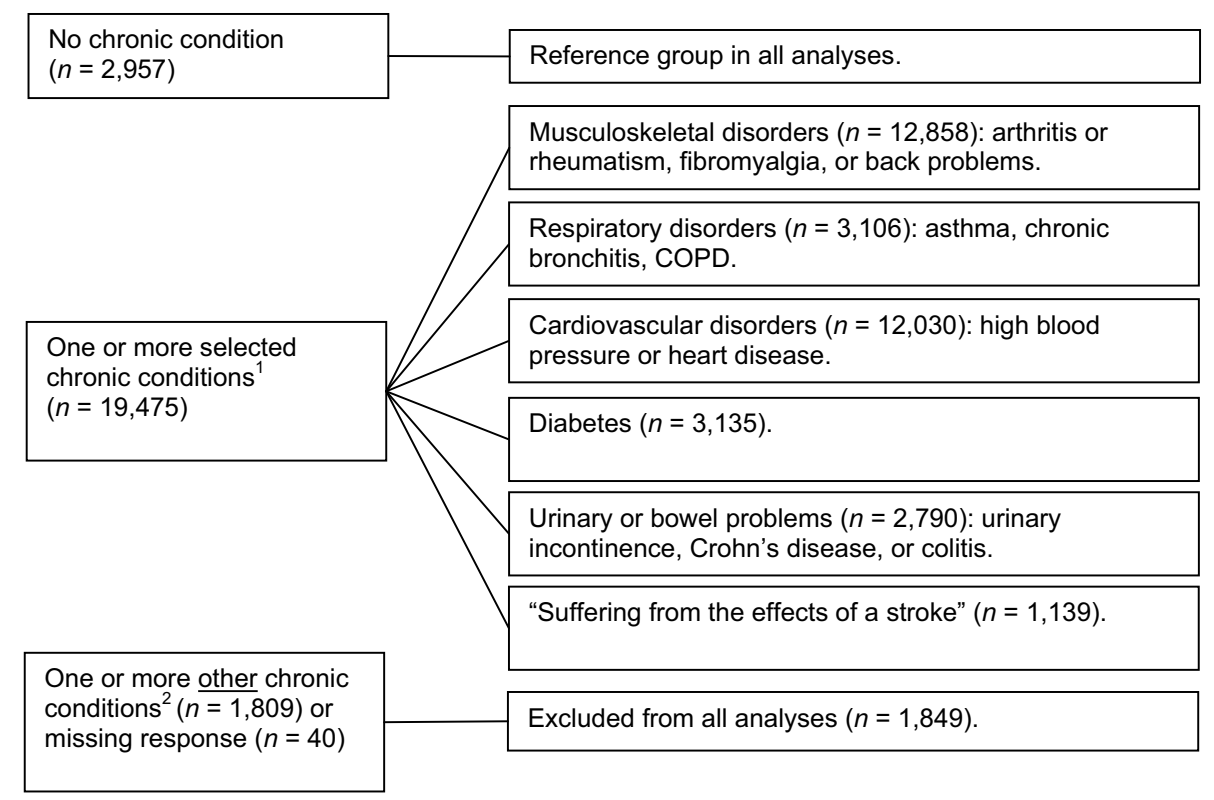

\section{Figure I}

Classification of chronic conditions in the sample of older adults. Notes: $\mathrm{N}=24,28 \mathrm{I}$.

I The following selected chronic conditions were included: asthma, fibromyalgia, arthritis or rheumatism, back problems, high blood pressure, chronic bronchitis, emphysema or chronic obstructive pulmonary disease (COPD), diabetes, heart disease, cancer, stroke, urinary incontinence, Crohn's disease or colitis, Alzheimer's disease or other dementia, Parkinson's disease, multiple sclerosis.

2 Excluded from all analyses were older adults who did not have any of the above chronic conditions but who did report having food or other allergies, migraine headaches, epilepsy, stomach or intestinal ulcers, cataracts, glaucoma, a thyroid condition, chronic fatigue syndrome, chemical sensitivities, or any other long-term chronic condition diagnosed by a health care professional. 
Table I: Description of the chronic condition groups

\begin{tabular}{|c|c|c|c|c|c|c|c|c|}
\hline \multirow[b]{2}{*}{ Category } & \multirow[b]{2}{*}{$\begin{array}{l}\text { No chronic } \\
\text { condition } \\
(n=2,639)\end{array}$} & \multirow[b]{2}{*}{$\begin{array}{c}\text { One or more } \\
\text { Chronic } \\
\text { conditions } \\
(n=|7,3| 4)\end{array}$} & \multicolumn{6}{|c|}{ Chronic condition groups } \\
\hline & & & $\begin{array}{l}\text { Respiratory } \\
\text { disorders } \\
(n=2,722)\end{array}$ & $\begin{array}{l}\text { Musculo- skeletal } \\
\text { disorders } \\
(n=11,473)\end{array}$ & $\begin{array}{c}\text { Cardio- vascular } \\
\text { disorders } \\
(n=10,741)\end{array}$ & $\begin{array}{l}\text { Diabetes } \\
(n=2,754)\end{array}$ & $\begin{array}{c}\text { Urinary or } \\
\text { bowel disorders } \\
(n=2,399)\end{array}$ & $\begin{array}{l}\text { Stroke } \\
(n=894)\end{array}$ \\
\hline \multicolumn{9}{|l|}{ Activity } \\
\hline$\geq \mathrm{I}, 000 \mathrm{Kcal} /$ week & $35.1 \%$ & $25.8 \%$ & $20.7 \%$ & $24.8 \%$ & $24.7 \%$ & $24.3 \%$ & $20.0 \%$ & $17.2 \%$ \\
\hline \multicolumn{9}{|l|}{ Age } \\
\hline $65-74$ yrs & $69.7 \%$ & $58.3 \%$ & $58.1 \%$ & $57.4 \%$ & $56.3 \%$ & $61.2 \%$ & $48.9 \%$ & $43.1 \%$ \\
\hline $75-79$ yrs & $17.1 \%$ & $21.2 \%$ & $22.2 \%$ & $21.3 \%$ & $22.5 \%$ & $21.8 \%$ & $21.9 \%$ & $26.4 \%$ \\
\hline$>84 \mathrm{yrs}$ & $13.2 \%$ & $20.5 \%$ & $19.7 \%$ & $21.3 \%$ & $21.2 \%$ & $17.0 \%$ & $29.2 \%$ & $30.5 \%$ \\
\hline \multicolumn{9}{|l|}{ Sex } \\
\hline Female & $46.2 \%$ & $59.6 \%$ & $56.9 \%$ & $65.0 \%$ & $59.1 \%$ & $50.8 \%$ & $68.3 \%$ & $50.7 \%$ \\
\hline \multicolumn{9}{|l|}{ Smoking } \\
\hline Yes & $16.7 \%$ & $11.6 \%$ & $15.6 \%$ & $11.8 \%$ & $10.1 \%$ & $9.0 \%$ & $11.6 \%$ & $11.5 \%$ \\
\hline \multicolumn{9}{|l|}{ Alcohol use } \\
\hline $\begin{array}{l}\text { Does not use } \\
\text { alcohol }\end{array}$ & $28.0 \%$ & $34.4 \%$ & $37.8 \%$ & $34.5 \%$ & $36.0 \%$ & $47.1 \%$ & $37.2 \%$ & $44.8 \%$ \\
\hline$<2$ times/month & $18.2 \%$ & $21.7 \%$ & $20.3 \%$ & $22.3 \%$ & $21.7 \%$ & $21.7 \%$ & $24.6 \%$ & $19.8 \%$ \\
\hline 2 to 3 times/month & $14.4 \%$ & $12.9 \%$ & $11.9 \%$ & $12.8 \%$ & $12.8 \%$ & $10.3 \%$ & $12.5 \%$ & $10.8 \%$ \\
\hline$>3$ times/month & $39.4 \%$ & $31.0 \%$ & $30.1 \%$ & $30.4 \%$ & $29.5 \%$ & $21.0 \%$ & $25.7 \%$ & $24.7 \%$ \\
\hline \multicolumn{9}{|l|}{ Obesity } \\
\hline $\mathrm{BMI}<18.5$ & $55.6 \%$ & $42.5 \%$ & $42.3 \%$ & $40.6 \%$ & $39.7 \%$ & $30.9 \%$ & $41.8 \%$ & $46.2 \%$ \\
\hline BMI I $8.5-25$ & $2.8 \%$ & $3.1 \%$ & $4.4 \%$ & $3.1 \%$ & $2.6 \%$ & $1.2 \%$ & $3.3 \%$ & $4.8 \%$ \\
\hline $\mathrm{BMI} \geq 25$ & $41.7 \%$ & $54.4 \%$ & $53.4 \%$ & $56.2 \%$ & $57.8 \%$ & $67.9 \%$ & $55.0 \%$ & $49.0 \%$ \\
\hline
\end{tabular}

Notes: $N=19,953$, including those older adults who had no chronic conditions or who had one of the selected chronic conditions and for whom there was no missing data for any of the variables in our analyses.

these attributes. The resulting ordinal variables were collapsed into dichotomous variables as shown in Table 2.

\section{Independent variables}

The respondents were asked about the frequency and amount of time that they engaged in physical leisure activities over the past three months (e.g., specific sports, gardening, exercise classes, etc.). A score for leisure-time physical activity was obtained by calculating weekly energy expenditure (kilocalories (Kcal) per week) based on the metabolic equivalents for each of the self-reported leisure activities [23]. We used the guidelines provided in the US Surgeon General's 1996 report as the basis for collapsing this variable so as to specifically compare those who had an energy expenditure of less than 1,000 Kcal per week to those who met the minimally recommended $1,000 \mathrm{Kcal}$ of weekly energy expenditure [24].

Tobacco use, alcohol consumption, and obesity were included as additional health-related covariates in our analyses. Older adults who reported smoking daily or occasionally at the time of the survey were compared to those who did not smoke. Alcohol consumption was assessed based on responses to the question "During the past 12 months, how often did you drink alcoholic beverages?" This variable was collapsed into four categories: 1) no alcohol consumption, 2) between one and three times a month, 3) once a week, and 4) more than once a week. The body mass index (BMI) was used to classify the older adults as being of normal weight (BMI $\geq 18.5$ and $<25$ ), underweight (BMI $<18.5$ ), or overweight or obese $(\geq 25)$. The respondent's age and sex were included as demographic covariates.

\section{Analytical approach}

We used ordinary least squares regression to estimate the relationships between having a chronic condition, physical activity, and the HUI3 score while controlling for the covariates mentioned above. As shown in Figure 2, the HUI3 score was regressed on the chronic condition variable, and physical activity was specified as a mediator of this relationship. The Pratt-Index $(d)$ [25] was used to partition the $R$-square so as to determine the relative importance of the variables explaining the HUI3 score. This index was calculated by multiplying the standardized regression coefficients by the corresponding correlations and dividing that value by the $R$-square. Thus, the PrattIndex value signifies the proportion of the $R$-square that is attributable to each of the variables in the model. We subsequently used binary logistic regression to examine the mediating effects of leisure-time physical activity independently for specific HUI3 attributes. The fit of the logistic models was assessed based on the likelihood ratio chi- 
Table 2: Bivariate associations among the HUI3 attributes having a chronic condition

\begin{tabular}{|c|c|c|c|}
\hline Variable & $\begin{array}{l}\text { No chronic condition } \\
\quad(n=2,639)\end{array}$ & $\begin{array}{l}\text { One or more chronic conditions } \\
\qquad(n=|7,3| 4)\end{array}$ & $\begin{array}{l}\text { Odds ratiol } \\
(95 \% \mathrm{Cl})\end{array}$ \\
\hline \multicolumn{4}{|l|}{ Mobility } \\
\hline No difficulty walking (referent) & $97.1 \%$ & $84.0 \%$ & 1.00 \\
\hline Difficulty walking or unable to walk & $2.9 \%$ & $16.0 \%$ & $6.4(4.7-8.7)$ \\
\hline \multicolumn{4}{|l|}{ Dexterity } \\
\hline Full use of hands and fingers (referent) & $99.8 \%$ & $97.8 \%$ & 1.00 \\
\hline Any limitation in the use of hands or fingers & $0.2 \%$ & $2.2 \%$ & $9.6(3.7-24.9)$ \\
\hline \multicolumn{4}{|l|}{ Emotion } \\
\hline Happy or somewhat happy (referent) & $98.7 \%$ & $94.7 \%$ & 1.00 \\
\hline Somewhat or very unhappy & $1.3 \%$ & $5.4 \%$ & $4.3(2.7-6.8)$ \\
\hline \multicolumn{4}{|l|}{ Cognition } \\
\hline No cognitive limitations (referent) & $80.6 \%$ & $66.7 \%$ & 1.00 \\
\hline Any cognitive limitations & $19.4 \%$ & $33.3 \%$ & $2.1(1.8-2.4)$ \\
\hline \multicolumn{4}{|l|}{ Pain } \\
\hline Free of pain or discomfort (referent) & $94.9 \%$ & $69.3 \%$ & 1.00 \\
\hline Mild, moderate, or severe pain & $5.1 \%$ & $30.7 \%$ & $8.3(6.2-11.0)$ \\
\hline
\end{tabular}

Notes: $N=19,953$.

I Bivariate logistic regression was used to calculate the confidence intervals.

square and the likelihood ratio $R^{2}$ (also known as McFadden's $\left.R^{2}\right)[26]$.

The degree of mediation was determined by calculating the indirect effect as the product of the coefficients of the relationships between the HUI3 attributes and physical activity and having a chronic condition [27]. The standard error for the indirect effect was estimated using the delta method, which is similar to the approach of variance estimation used in the Sobel's test for mediating effects [28]. A simulation study by MacKinnon and Dwyer showed that the delta method led to accurate estimates of indirect effects and their standard errors when using binary data [28]. We followed their recommendations to evaluate the degree of mediation as the percentage of the total effect that could be attributed to the indirect effect.

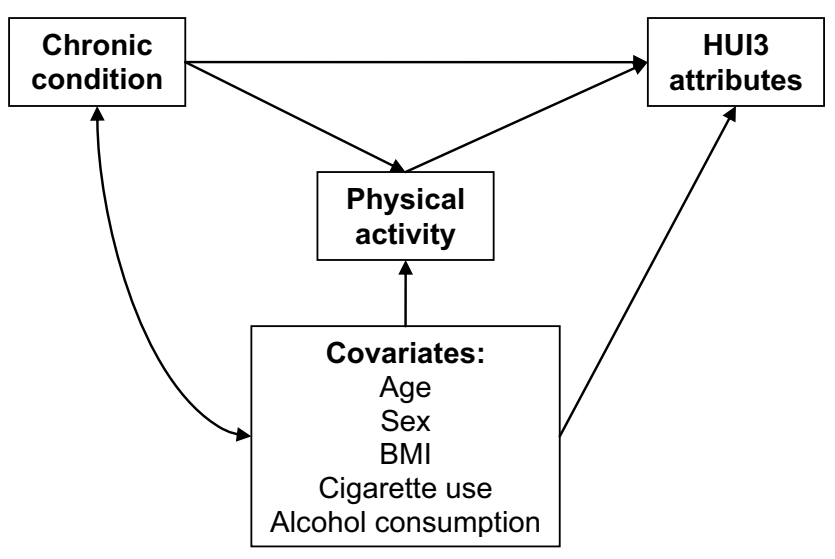

Figure 2

Heuristic diagram of hypothesized relationships.
The SAS 9.1 software package [29] was used to obtain the maximum likelihood estimates for each of the models. The bootstrapped sampling weights provided by Statistics Canada were used to obtain parameter estimates and their standard errors based on 500 replications of each model. All models were estimated using listwise deletion resulting in the exclusion of 2,479 (11.1\%) respondents due to missing responses for one or more of the analysis variables. The parameter estimates were compared to those based on full information maximum likelihood estimation (FIML) (available in the Mplus 4.2 [30] software package) by using all available data to assess whether the estimates may have been biased by non-random missing data patterns ( $n=21,736$; excluding $696(3.1 \%)$ respondents who did not provide any information regarding their HUI3 scores or any of the explanatory variable) $[31,32]$.

\section{Results}

\section{Sample description and bivariate associations}

Most of the older adults (79\%) had at least one of the chronic conditions that were considered in our study, $8 \%$ had a chronic condition other than the ones that were considered in our study, and $13 \%$ had no chronic condition (Figure 1). Only $25 \%$ of the older adults achieved the minimally recommended activity level of 1,000 Kcal per week $(64 \%$ did not achieve the recommended activity level and $11 \%$ did not answer some or all questions about their leisure-time physical activity). Descriptive findings pertaining to each of the chronic condition groups are shown in Table 1.

The distribution of the HUI3 score was negatively skewed with a mean of $0.79(\mathrm{SD}=0.25)$ and a median of $0.91(\mathrm{~N}$ $=19,953$ ). With respect to specific HUI3 attributes, most older adults reported having no limitations in cognition 
$(69 \%)$, mobility (86\%), and dexterity (98\%). In addition, $73 \%$ reported having no pain, and $95 \%$ reported being happy or somewhat happy in life.

Those who had a chronic condition had relatively lower scores for each of the HUI3 attributes in comparison to those who had no chronic condition (Table 2). At the time of the survey, they were also less likely to have used tobacco, less likely to have consumed alcohol and more likely to be overweight (Figure 3). Fewer older adults who had a chronic condition achieved the recommended physical activity level of 1,000 Kcal per week relative to those older adults who did not have a chronic condition. The corresponding odds ratio (OR) in the overall sample was $1.6(95 \% \mathrm{CI}=1.5-1.8)$, and the ORs ranged from 1.6 to 2.6 in the chronic condition subsamples (Figure 4).

\section{Multivariate analysis results}

The F-test of model fit for the variables explaining the total HUI3 score was statistically significant (F (11, $19,941)=254, p<0.01, R^{2}=12 \%$ ) (Table 3 ). The HUI3 score was predominantly explained by differences in age (Pratt Index $=0.35$ ), having a chronic condition (Pratt Index $=0.28$ ), leisure-time physical activity (Pratt Index = 0.19 ), and alcohol consumption (Pratt Index $=0.15$ ). Although the effects of the other variables were statistically significant, they only accounted for a total of $2 \%$ of the explained variance. Relatively lower HUI3 scores were observed for those who had a chronic condition ( $b=$ $0.13, p<0.01$ ), and relatively higher HUI3 scores were observed for those who were physically active $(b=0.07, p$
$<0.01)$ after controlling for differences in age, gender, tobacco use, alcohol consumption, and obesity.

The relationship between having a chronic condition and leisure-time physical activity was examined to determine whether physical activity mediated the negative impact of having a chronic condition on the HUI3 score. The likelihood ratio test of global model fit for variables explaining the physical activity was statistically significant $\left(\operatorname{LR} \chi^{2}(10)\right.$ $=1,878.80, p<0.01$, LR $R^{2}=8 \%$ ). Physical activity was significantly associated with differences in age, alcohol consumption, smoking status, and having a chronic condition (last column Table 3). Thus, the negative impact of having a chronic condition was partially mediated by physical activity (14\% mediation), and the corresponding indirect effect was statistically significant $(p<$ 0.01) after controlling for the covariates (Table 3). The indirect effects for the HUI3 attributes were statistically significant for mobility limitations, pain, and emotional wellbeing (Table 3). The average percentages of the total impact of having a chronic condition that could be attributed to the mediating role of physical activity were $18 \%$ for mobility challenges, $13 \%$ for emotional problems, and $5 \%$ for pain. We did not observe statistically significant $(p<0.01)$ indirect effects for dexterity problems and cognition.

The above associations were examined independently in each of the six chronic condition subsamples (Table 4). Having a chronic condition was significantly associated with a relative increase in mobility limitations, pain, and emotional problems in all chronic condition subsamples.

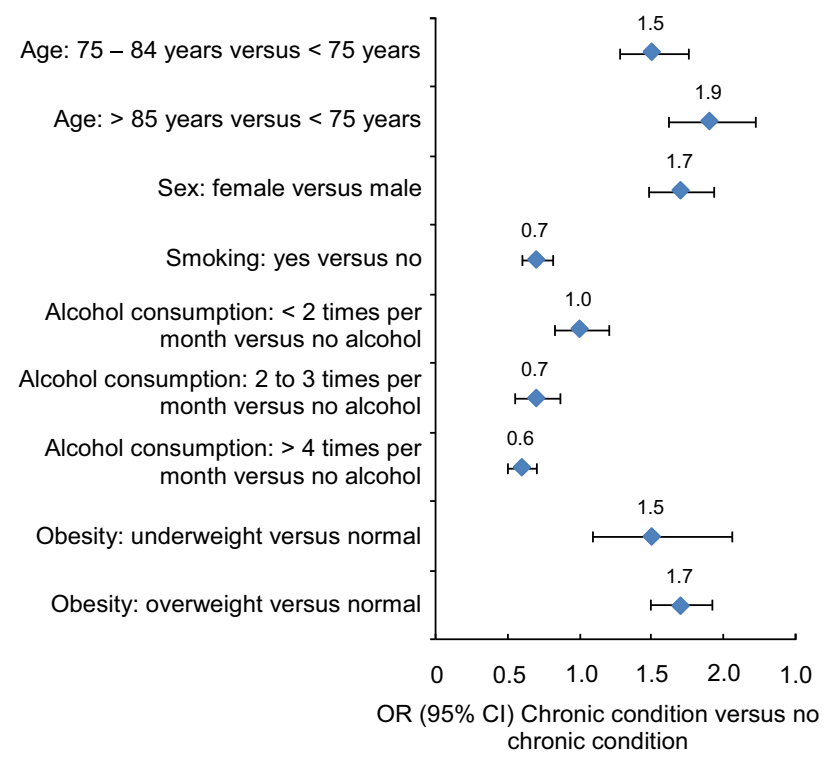

Figure 3

Odds ratios for covariates. Notes: $N=19,953$. 


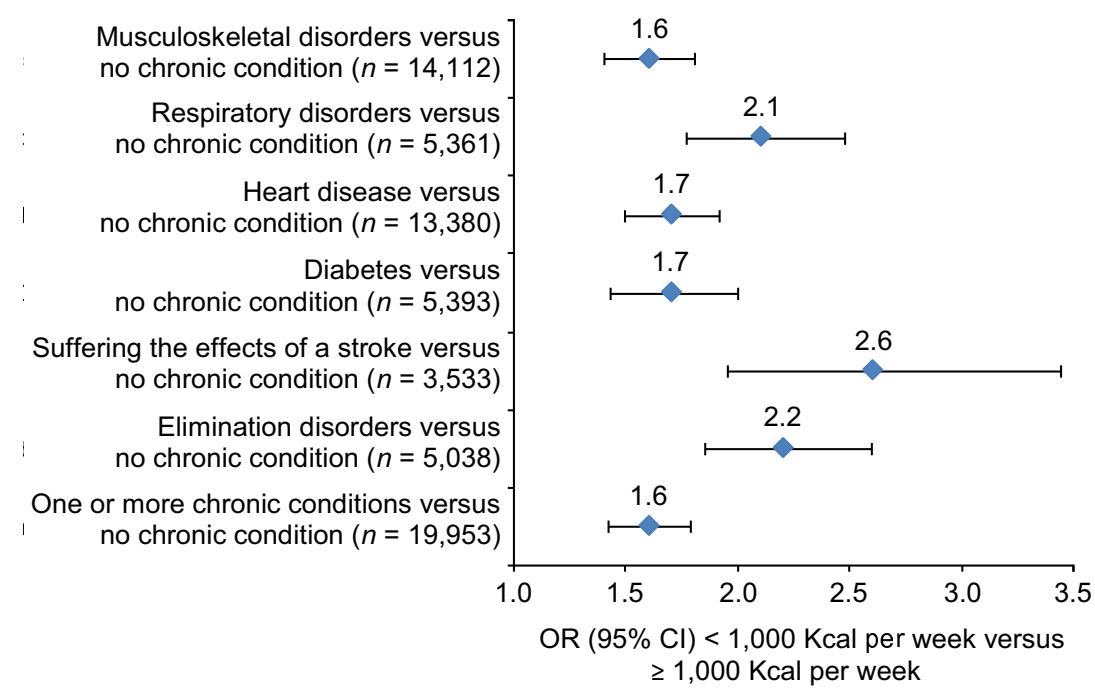

Figure 4

Odds ratios for physical activity in the chronic condition subsamples.

Table 3: Regression model results in the full sample

\begin{tabular}{|c|c|c|c|c|c|}
\hline \multirow[b]{2}{*}{ Variables } & \multicolumn{5}{|c|}{ Dependent variables } \\
\hline & $\begin{array}{l}\text { HUl total score } \\
\text { b(se) }\end{array}$ & $\begin{array}{c}\text { Mobility } \\
\text { OR }(95 \% \mathrm{Cl})\end{array}$ & $\begin{array}{c}\text { Pain } \\
\text { OR }(95 \% \mathrm{Cl})\end{array}$ & $\begin{array}{l}\text { Emotion } \\
\text { OR }(95 \% \mathrm{Cl})\end{array}$ & $\begin{array}{l}\text { Physical activity } \\
\text { OR }(95 \% \mathrm{Cl})\end{array}$ \\
\hline \multicolumn{6}{|l|}{$\begin{array}{l}\text { Physical activity (referent }=\geq 1,000 \mathrm{Kcal} / \\
\text { week) }\end{array}$} \\
\hline$<\mathrm{I}, 000 \mathrm{Kcal} /$ week & $-0.07(0.00)$ & $3.6(4.3-3.0)$ & $1.5(1.7-1.3)$ & $2.2(1.6-3.0)$ & - \\
\hline \multicolumn{6}{|l|}{ Age (referent $=65-74 \mathrm{yrs})$} \\
\hline $75-84$ yrs & $-0.04(0.01)$ & $2.0(1.8-2.4)$ & $1.0(0.9-1.2)$ & $\mathrm{I} . \mathrm{I}(0.8-\mathrm{I} .5)$ & $1.6(1.4-1.9)$ \\
\hline$>84$ yrs & $-0.12(0.01)$ & $4.9(4.2-5.6)$ & $1.1(1.0-1.2)$ & $1.3(1.0-1.6)$ & $2.3(2.0-2.6)$ \\
\hline \multicolumn{6}{|l|}{ Sex $($ referent $=$ male $)$} \\
\hline Female & $0.02(0.01)$ & $0.9(0.8-1.0)$ & $1.3(1.2-1.4)$ & $0.9(0.7-1.1)$ & $2.3(2.1-2.6)$ \\
\hline \multicolumn{6}{|c|}{ Smoking status (referent $=$ does not smoke) } \\
\hline Smokes daily or occasionally & $-0.04(0.01)$ & $1.5(1.2-1.8)$ & $1.2(1.1-1.4)$ & $1.8(1.4-2.3)$ & $2.0(1.7-2.3)$ \\
\hline \multicolumn{6}{|c|}{ Alcohol use (referent $=$ does not use alcohol) } \\
\hline Less than two times/month & $0.03(0.01)$ & $0.9(0.8-1.0)$ & $0.9(0.8-1.0)$ & $0.7(0.5-1.0)$ & $0.8(0.7-1.0)$ \\
\hline Two or three times/month & $0.06(0.01)$ & $0.6(0.5-0.7)$ & $0.8(0.6-0.9)$ & $0.5(0.3-0.8)$ & $0.7(0.6-0.8)$ \\
\hline Four or more times/month & $0.07(0.01)$ & $0.6(0.5-0.7)$ & $0.7(0.6-0.8)$ & $0.4(0.3-0.6)$ & $0.6(0.5-0.6)$ \\
\hline \multicolumn{6}{|l|}{ Obesity (referent $=$ between 18.5 and 25 ) } \\
\hline Less than 18.5 & $-0.06(0.02)$ & $1.6(1.2-2.2)$ & $1.4(1.1-1.8)$ & $2.1(1.4-3.2)$ & $3.7(2.6-5.4)$ \\
\hline More than or equal to 25 & $-0.01(0.00)$ & $1.5(1.3-1.7)$ & $1.2(1.1-1.3)$ & $0.9(0.8-1.2)$ & $1.0(0.9-1.1)$ \\
\hline \multicolumn{6}{|c|}{$\begin{array}{l}\text { Chronic condition(s) (referent }=\text { no chronic } \\
\text { conditions) }\end{array}$} \\
\hline One or more chronic conditions & $-0.13(0.00)$ & $5.1(3.8-7.0)$ & $7.6(5.7-10.1)$ & $4.0(2.5-6.3)$ & $1.3(1.2-1.5)$ \\
\hline Indirect effect ${ }^{\prime}$ & $-0.02(0.01)$ & $1.4(1.2-1.7)$ & $1.1(1.1-1.2)$ & $1.2(1.1-1.2)$ & - \\
\hline$\%$ mediated by physical activity ${ }^{2}$ & $14 \%$ & $18 \%$ & $5 \%$ & $13 \%$ & - \\
\hline$R^{2}\left(\operatorname{LR} R^{2}\right)$ & $12 \%$ & $(15 \%)$ & (6\%) & $(6 \%)$ & $(8 \%)$ \\
\hline Likelihood ratio chi-square $(\mathrm{Df}=\mathrm{II})$ & $\mathrm{n} / \mathrm{a}$ & $2,358.59$ & $1,444.94$ & 423.90 & $1,878.80$ \\
\hline \multicolumn{6}{|c|}{$\begin{array}{l}\text { Notes: } N=19,953 \text {, including those older adults who had no chronic conditions or one of the selected chronic conditions and for whom there was no } \\
\text { missing data for any of the variables in our analyses. Only the results for the HUl3 attributes with statistically significant indirect effects }(p<0.0 \mathrm{I}) \text { are } \\
\text { shown. The reference groups for mobility, pain, and emotion are the same as in Table } 2 \text {. } \\
\text { I The indirect effect of having a chronic condition versus no chronic condition as mediated by physical activity. } \\
2 \text { Percentage of the total effect of having a chronic condition that is attributed to the mediating role of physical activity after controlling for the covariates } \\
\text { (based on the unexponentiated regression weights). }\end{array}$} \\
\hline
\end{tabular}


Table 4: Odds ratios and \% mediation for selected HUI3 attributes in the chronic condition subsamples

\begin{tabular}{|c|c|c|c|c|c|}
\hline \multirow[b]{2}{*}{ Independent variables } & \multicolumn{5}{|c|}{ HUI3 attributes (dependent variables) } \\
\hline & $\begin{array}{l}\text { Dexterity } \\
\text { OR }(95 \% \mathrm{Cl})\end{array}$ & $\begin{array}{l}\text { Emotional } \\
\text { wellbeing } \\
\text { OR }(95 \% \mathrm{CI})\end{array}$ & $\begin{array}{l}\text { Cognition } \\
\text { OR }(95 \% \mathrm{Cl})\end{array}$ & $\begin{array}{c}\text { Pain } \\
\text { OR }(95 \% \mathrm{Cl})\end{array}$ & $\begin{array}{c}\text { Mobility } \\
\text { OR }(95 \% \mathrm{Cl})\end{array}$ \\
\hline $\begin{array}{l}\text { Musculoskeletal disorders versus no chronic } \\
\text { condition }(n=|4,| \mid 2)^{\prime}\end{array}$ & II.0 (4.3- 28.5) & $4.7(2.9-7.6)$ & $2.2(2.0-2.5)$ & $12.0(9.0-16.1)$ & $6.6(4.8-9.0)$ \\
\hline Physical activity $<1,000 \mathrm{Kcal} /$ week $^{2}$ & $1.5(1.0-2.3)$ & $2.3(1.6-3.3)$ & I.I (I.0 - I.3) & $1.4(1.2-1.7)$ & $3.7(3.0-4.5)$ \\
\hline$\%$ mediation $^{3}$ & $5 \%$ & $13 \% *$ & $4 \%$ & $4 \% *$ & $16 \% *$ \\
\hline $\begin{array}{l}\text { Respiratory disorders versus no chronic } \\
\text { condition }(n=5,36 \mathrm{I})^{I}\end{array}$ & $10.4(3.7-28.9)$ & $5.0(3.0-8.1)$ & $2.2(1.8-2.6)$ & $10.7(8.0-14.5)$ & $7.6(5.4-10.7)$ \\
\hline Physical activity $<1,000 \mathrm{Kcal} /$ week $^{2}$ & $0.8(0.4-1.5)$ & $2.0(0.9-4.5)$ & $1.2(1.0-1.5)$ & $\mathrm{I} .4(\mathrm{I} .0-\mathrm{I} .8)$ & $3.9(2.5-6.0)$ \\
\hline$\%$ mediation $^{3}$ & $0 \%$ & $20 \%$ & $13 \%$ & $7 \%$ & $27 \% *$ \\
\hline $\begin{array}{l}\text { Cardiovascular disorders versus no chronic } \\
\text { condition }(n=\mid 3,380)^{\mid}\end{array}$ & $7.8(3.0-20.0)$ & $4.0(2.5-6.4)$ & $1.9(1.7-2.2)$ & $7.2(5.4-9.5)$ & $5.6(4.1-7.7)$ \\
\hline Physical activity $<1,000 \mathrm{Kcal} /$ week $^{2}$ & $1.4(0.9-2.2)$ & $2.1(1.4-3.2)$ & $1.2(1.0-1.3)$ & $1.6(1.3-1.9)$ & $3.3(2.6-4.1)$ \\
\hline$\%$ mediation $^{3}$ & $5 \%$ & $16 \% *$ & $7 \%$ & $8 \% *$ & $19 \% *$ \\
\hline $\begin{array}{l}\text { Diabetes versus no chronic condition }(n= \\
5,393)^{\prime}\end{array}$ & $10.6(4.3-26.5)$ & $5.0(3.0-8.5)$ & $1.9(1.6-2.3)$ & $7.1(5.2-9.7)$ & $6.6(4.8-9.2)$ \\
\hline Physical activity $<1,000 \mathrm{Kcal} /$ week $^{2}$ & $1.2(0.5-3.1)$ & $1.9(0.8-4.1)$ & $1.2(1.0-1.5)$ & $1.7(1.3-2.3)$ & $3.5(2.3-5.3)$ \\
\hline$\%$ mediation $^{3}$ & $3 \%$ & $13 \%$ & $10 \%$ & $10 \% *$ & $21 \% *$ \\
\hline $\begin{array}{l}\text { "Suffering the effects of a stroke" versus no } \\
\text { chronic condition }(n=3,533)\end{array}$ & $24.9(7.9-78.1)$ & $9.4(5.1-17.5)$ & $3.4(2.7-4.3)$ & $12.4(8.7-17.7)$ & $18.2(12.7-26.1)$ \\
\hline Physical activity $<\mathrm{I}, 000 \mathrm{Kcal} /$ week $^{2}$ & $0.6(0.2-2.4)$ & I.2(0.4- 3.6) & $\mathrm{I} .0(0.8-\mathrm{I} .4)$ & $1.3(0.8-2.0)$ & $2.6(1.5-4.6)$ \\
\hline$\%$ mediation $^{3}$ & $0 \%$ & $5 \%$ & $3 \%$ & $7 \%$ & $20 \% *$ \\
\hline $\begin{array}{l}\text { Urinary or bowel disorders versus no } \\
\text { chronic condition }(n=5,038)^{\prime}\end{array}$ & I5.3 (5.8-40.5) & $7.7(4.5-13.1)$ & $3.1(2.6-3.8)$ & $14.4(10.5-19.7)$ & $9.9(7.1-13.9)$ \\
\hline Physical activity $<1,000 \mathrm{Kcal} /$ week $^{2}$ & $\mathrm{I} .0(0.6-\mathrm{I} .8)$ & I.2 $(0.7-2.1)$ & I.I $(0.9-1.4)$ & $2.0(1.5-2.7)$ & $2.9(2.0-4.2)$ \\
\hline$\%$ mediation $^{3}$ & $0 \%$ & $4 \%$ & $6 \%$ & $12 \% *$ & $20 \% *$ \\
\hline \multicolumn{6}{|c|}{$\begin{array}{l}\text { All odds ratios are adjusted for age, sex, cigarette use, alcohol consumption, and obesity. The } \\
\text { in Table } 2 \text {. } \\
\text { I Referent }=\text { no chronic condition. } \\
2 \text { Referent }=\geq 1,000 \mathrm{Kcal} / \text { week. } \\
3 \text { Percentage of the total effect that is attributable to the mediating effect of physical activity. } \\
\text { * Statistically significant indirect effects }(p<0.0 \mathrm{I}) \text {. }\end{array}$} \\
\hline
\end{tabular}

The adjusted ORs for the effect of having a chronic condition on leisure-time physical activity when controlling for the covariates ranged from $1.3(95 \% \mathrm{CI}=1.1-1.5)$ for older adults with a musculoskeletal disorder to $2.1(95 \%$ $\mathrm{CI}=1.6-2.8)$ for older adults who suffered the consequences of a stroke. Those who were more physically active reported relatively fewer mobility limitations (OR ranging from 2.6 to 3.9) and less pain (OR ranging from 1.3 to 2.0 ) in the chronic condition subsamples (Table 4). Increased physical activity was also associated with a relative increase in emotional wellbeing and relatively fewer cognitive problems and dexterity limitations in some of the chronic condition subsamples. The indirect effects were statistically significant for mobility limitations (ranging from 16\% in the musculoskeletal disorders subsample to $27 \%$ in the respiratory disorders subsample) in all of the chronic condition subsamples (last column
Table 4). Similar results with respect to the magnitude of the parameters were obtained when these analyses were replicated using FIML.

\section{Discussion}

To our knowledge, this is the first study that has specifically examined degree to which the negative impact of chronic conditions on quality of life in older adults could be attributed to a lack of physical activity. The results suggest that physical activity partially mediates the impact of chronic conditions on several health outcomes that are important to quality of life. Physical activity of at least $1,000 \mathrm{Kcal}$ per week was associated with relatively fewer mobility limitations, reduced pain, and greater emotional wellbeing (i.e., happiness). The clinical relevance of the mediating role of physical activity can be inferred by comparing the magnitude of the indirect effect to that of the 
total effect, which indicated up to $27 \%$ mediation for mobility limitation, up to $12 \%$ mediation for pain, and up to $16 \%$ mediation for emotional wellbeing. These findings concur with those of other studies. For example, adequate physical activity was associated with a significant reduction in the number of days of poor physical and mental health status in adults with arthritis [15].

The US Center for Disease Control and the American College of Sports Medicine guidelines [33] recommended that individuals should engage in 30 minutes or more of moderate-intensity physical activity on a daily basis (equivalent to approximately $1,400 \mathrm{Kcal} /$ week) while the US Surgeon General's 1996 report classified moderate physical activity as more than 1,000 Kcal/week [24]. We found a low level of participation in leisure-time physical activity regardless of chronic disease status among older Canadians. Specifically, only 35\% of older adults without any chronic condition and $26 \%$ of those with one or more chronic conditions met the 1,000 Kcal/week criterion.

Epidemiological data have established that physical inactivity decreases the incidence of at least 17 unhealthy conditions, most of which are chronic conditions or risk factors [7]. Our study further elucidates the importance of physical activity for older adults who have a chronic condition. We found that older adults with chronic conditions who were physical active (i.e., leisure-time physical activity of at least 1,000 Kcal per week) reported better health outcomes related to mobility, pain, and emotional wellbeing than those who were physical inactive. Leisuretime physical activity likely mediates the negative association between chronic conditions and these specific selfreported health outcomes in older adults by: 1) maintaining or augmenting physiological functions (e.g., prevention of sarcopenia); 2) reducing the likelihood of acquiring additional chronic conditions; 3 ) delaying the progression of current chronic condition(s); and 4) improving mental health and sense of wellbeing. In sum, physical activity beneficially affects the human body in a multifactorial manner.

Regular physical activity not only directly promotes mobility in older adults via mechanisms such as improved muscle strength and postural balance but also indirectly by, for example, reducing the risk for falls and fractures $[34,35]$. Maintaining the capacity for independent mobility and living is important to older adults and contributes to their general sense of emotional wellbeing $[36,37]$. Physical activity can enhance emotional wellbeing via increases in: 1 ) beta endorphins; 2 ) the availability of brain neurotransmitters (e.g. serotonin); and 3) selfefficacy [38]. In addition, physical activity may mediate the negative association between chronic conditions and health outcomes by reducing the likelihood of acquiring additional chronic conditions and delaying the progression of current chronic condition(s). Most prevalent chronic conditions have an association with physical inactivity, and a number of risk factors for chronic conditions are precipitated by physical inactivity (e.g., obesity [39] and insulin resistance [40]).

Unfortunately, individuals with chronic conditions are at the highest risk of physical inactivity [24] - placing these individuals at greater risk for acquiring additional chronic conditions. According to Booth and coworkers [7], physical inactivity is the key environmental factor contributing to the substantial increase in the incidence of chronic conditions in the latter part of the $20^{\text {th }}$ century. Thus, physical activity can prevent the onset of chronic conditions. Our findings suggest that physical activity could also be beneficial for older adults who already have one or more chronic conditions. These findings provide further support for health promotion programs that facilitate or encourage increased leisure-time physical activity in older people with chronic conditions.

In this study, physical activity is measured as the time spent performing leisure-time activities. Despite the comprehensive nature of this information, daily activities performed by individuals are not represented in these data and therefore physical activity was conservatively estimated. In addition, some respondents may not have been able to accurately recall all their leisure-time physical activities for a period of three months. This may explain why the magnitude of the mediation effect that we observed in this study was smaller than we had anticipated. We specifically expected that the OR for the association between having a chronic condition and physical activity would have been larger. Non-response bias may also have contributed to these results (e.g., older adults with severe physical or mental health problems may have been less likely to complete the survey).

A few other limitations should be noted. Although the relationships were specified to examine the mediating effects of physical activity, the direction of these relationships could also operate in the reverse. The cross-sectional nature of the data does not allow us to confirm claims pertaining to the causality of these relationships. It seems just as likely that poor ambulation will lead to a decrease in physical activity which could lead to a variety of chronic conditions. In addition, the utility weights for the HUI3 may not be generalizable considering that they are based on a community sample of 504 adults in the city of Hamilton, Ontario, Canada [22]. Nevertheless, these weights were only used for calculating the total HUI3 scores; they were not used to measure each of the health attributes which were included as binary variables in our analyses. And, there is a lack of independence in our categories of 
chronic conditions. For instance individuals who have had a stroke are likely to have cardiovascular conditions as well. Finally, some chronic conditions that may impact quality of life in older adults (e.g., epilepsy and migraine headaches) were not included in our analyses.

\section{Conclusion}

We observed that older adults with chronic conditions are less likely to engage in leisure-time physical activities of at least 1,000 Kcal per week, and that association partially accounts for some negative consequences of chronic conditions, including mobility limitations, pain, and emotional problems. We recommend that increased attention be paid to physical activity as a potential health promotion modality for older adults with chronic conditions. Further studies are needed to determine the particular types of physical activities that are most beneficial for older adults with specific chronic conditions.

\section{Abbreviations}

BMI Body mass index

CI Confidence interval

CCHS Canadian Community Health Survey

FIML Full information maximum likelihood

HUI3 Health Utilities Index (Mark 3)

Kcal Kilocalories

LR Likelihood ratio

OR Odds ratio

SD Standard deviation

\section{Competing interests}

The author(s) declare that they have no competing interests.

\section{Authors' contributions}

RS designed and carried out the statistical analyses and drafted the manuscript. TLA assisted with the interpretation of the results and contributed to the writing and editing of multiple drafts. WCM conceived and designed the project, obtained funding, assisted with the interpretation of the results and contributed to the writing and editing of multiple drafts. CAM was involved in the design, assisted in the interpretation of results and edited multiple drafts of the manuscript. All authors read and approved the final manuscript.

\section{Acknowledgements}

We wish to acknowledge the Physical Activity and Chronic Conditions (PACC) Research Team for their support and contributions to the larger research project that gave rise to this study, Dr. David Mackinnon for his correspondence with us regarding the computation of mediating effects, and Dr. Peilin Shi for conducting preliminary analyses. This project was supported by a Canadian Institutes of Health Research (CIHR) Team Development Grant. WCM is a funded scholar supported by the CIHR Institute of Aging. TLA and CAM are Michael Smith Foundation for Health Research Scholars. CAM is a Canada Research Chair in Pharmaceutical Outcomes.

\section{References}

I. Gilmour H, Park J: Dependency, chronic conditions and pain in seniors. Health Rep 2006, I 6 Suppl:2I-3I.

2. Schnittker J: Chronic illness and depressive symptoms in late life. Soc Sci Med 2004/10/16 edition. 2005, 60(I): I 3-23.

3. Lyness JM, Niculescu A, Tu X, Reynolds CF, Caine ED: The relationship of medical comorbidity and depression in older, primary care patients. Psychosomatics 2006/09/09 edition. 2006, 47(5):435-439.

4. Leong IY, Farrell MJ, Helme RD, Gibson SJ: The relationship between medical comorbidity and self-rated pain, mood disturbance, and function in older people with chronic pain. I Gerontol A Biol Sci Med Sci 2007/05/25 edition. 2007, 62(5):550-555.

5. Bean JF, Vora A, Frontera WR: Benefits of exercise for community-dwelling older adults. Arch Phys Med Rehabil 2004, 85(7 Suppl 3):S31-42.

6. Centers for Disease Control and Prevention (CDC): Missed opportunities in preventive counseling for cardiovascular disease-United States, 1995. MMWR Morb Mortal Wkly Rep 1998, 47(5):91-5.

7. Booth FW, Gordon SE, Carlson CJ, Hamilton MT: Waging war on modern chronic diseases: primary prevention through exercise biology. J Appl Physiol 2000, 88(2):774-787.

8. Leveille SG, Guralnik JM, Ferrucci L, Langlois JA: Aging successfully until death in old age: opportunities for increasing active life expectancy. Am J Epidemiol 1999, I49(7):654-664.

9. Lee IM, Paffenbarger RS: Do physical activity and physical fitness avert premature mortality? Exerc Sport Sci Rev 1996, 24: I35-I7I.

10. DiLorenzo TM, Bargman EP, Stucky-Ropp R, Brassington GS, Frensch PA, LaFontaine T: Long-term effects of aerobic exercise on psychological outcomes. Prev Med I999, 28(I):75-85.

II. Greist JH, Klein MH, Eischens RR, Faris J, Gurman AS, Morgan WP: Running as treatment for depression. Compr Psychiatry 1979, 20(I):4I-54.

12. Blumenthal JA, Babyak MA, Moore KA, Craighead WE, Herman S, Khatri P, Waugh R, Napolitano MA, Forman LM, Appelbaum M, Doraiswamy PM, Krishnan KR: Effects of exercise training on older patients with major depression. Arch Intern Med 1999, I 59( I 9):2349-2356.

13. Babyak M, Blumenthal JA, Herman S, Khatri P, Doraiswamy M, Moore K, Craighead WE, Baldewicz TT, Krishnan KR: Exercise treatment for major depression: maintenance of therapeutic benefit at 10 months. Psychosom Med 2000, 62(5):633-638.

14. Centers for Disease Control and Prevention (CDC).: Centres for Disease Control and Prevention: Surveillance for selected public health indicators affecting older adults - United States. MMWR CDC Surveill Summ 1999, 48(SS8): [http:// www.cdc.gov/mmwr/PDF/SS/SS4808.pdf].

15. Abell JE, Hootman JM, Zack MM, Moriarty D, Helmick CG: Physical activity and health related quality of life among people with arthritis. J Epidemiol Community Health 2005, 59(5):380-385.

16. Brown DW, Balluz LS, Heath GW, Moriarty DG, Ford ES, Giles WH, Mokdad $\mathrm{AH}$ : Associations between recommended levels of physical activity and health-related quality of life. Findings from the 200I Behavioral Risk Factor Surveillance System (BRFSS) survey. Prev Med 2003, 37(5):520-528.

17. Beland $Y$ : Canadian community health survey: methodological overview. Health Rep 2002, I3(3):9-14.

18. Furlong WJ, Feeny DH, Torrance GW, Barr RD: The Health Utilities Index (HUI) system for assessing health-related quality of life in clinical studies. Ann Med 200I, 33(5):375-384. 
19. Schultz S E, Kopec I A: Impact of chronic conditions. Health Rep 2003, I 4(44|-53 [http://www.statcan.ca/english/studies/82-003/ archive/2003/14-4-c.pdf].

20. Torrance GW: Measurement of health state utilities for economic appraisal. J Health Econ 1986, 5(I): I-30.

21. Torrance GW, Boyle MH, Horwood SP: Application of multiattribute utility theory to measure social preferences for health states. Oper Res 1982, 30(6): 1043-1069.

22. Feeny D, Furlong W, Torrance GW, Goldsmith CH, Zhu Z, DePauw S, Denton M, Boyle M: Multiattribute and single-attribute utility functions for the Health Utilities Index Mark 3 system. Med Care 2002, 40(2): I I3-128.

23. Ainsworth BE, Haskell WL, Leon AS, Jacobs DR, Montoye HJ, Sallis JF, Paffenbarger RS: Compendium of physical activities: classification of energy costs of human physical activities. Med $\mathrm{Sc}$ Sports Exerc 1993, 25(1):7I-80.

24. US Department of Health and Human Services: Physical activity and health: a report of the surgeon general. 1996 [http:// www.cdc.gov/nccdphp/sgr/pdf/sgrfull.pdf]. Atlanta (GA), US Department of Health and Human Services, Centre for Disease Control and Prevention, National Centre for Chronic Disease Prevention and Health Promotion

25. Thomas $D R$, Hughes $E$, Zumbo BD: On variable importance in linear regression. Soc Indic Res 1998, 45:253-175.

26. Menard SW: Applied logistic regression analysis . 2nd edition. Thousand Oaks, Sage; 2002.

27. MacKinnon DP, Lockwood CM, Hoffman JM, West SG, Sheets V: A comparison of methods to test mediation and other intervening variable effects. Psychol Methods 2002, 7:83-104.

28. Mackinnon DP, Dwyer JH: Estimating mediated effects in prevention studies. Eval Rev 1993, 17:144-158.

29. SAS Institute: Statistical analysis software (version 9.2). Cary, NC, Author; 2005.

30. Muthén B, Muthén LK: MPlus (version 4.2). Los Angeles, Statmodel; 2006

31. Enders CK: Analyzing structural equation models with missing data. In Structural equation modeling: a second course Edited by: Hancock GR, Mueller RO. Greenwich , Information Age Publishing; 2006:3।3-342.

32. Allison PD: Missing data. Thousand Oaks, CA , Sage; 2002.

33. Pate RR, Pratt M, Blair SN, Haskell WL, Macera CA, Bouchard C, Buchner D, Ettinger W, Heath GW, King AC, et al.: Physical activity and public health. A recommendation from the Centers for Disease Control and Prevention and the American College of Sports Medicine. Jama 1995, 273:402-407.

34. Campbell AJ, Robertson MC, Gardner MM, Norton RN, Buchner DM: Falls prevention over 2 years: a randomized controlled trial in women 80 years and older. Age Ageing 1999, 28(6):5|3-5|8.

35. Campbell A]: Preventing fractures by preventing falls in older women. CMAJ 2002, I67(9): 1005-6.

36. Salkeld G, Cameron ID, Cumming RG, Easter S, Seymour J, Kurrle SE, Quine S: Quality of life related to fear of falling and hip fracture in older women: a time trade off study. BM] 2000 320(723I):34I-346.

37. Gold DT: The nonskeletal consequences of osteoporotic fractures. Psychologic and social outcomes. Rheum Dis Clin North Am 200I, 27(I):255-62.

38. Craft LL, Perna FM: The benefits of exercise for the clinically depressed. Prim Care Companion J Clin Psychiatry 2004, 6(3): I04- III.

39. Perusse L, Bouchard C: Genotype-environment interaction in human obesity. Nutr Rev 1999, 57(5 Pt 2):S3 I-7; discussion S37-8.

40. Howard BV: Insulin resistance and lipid metabolism. Am J Cardiol I999, 84( I A):28]-32]

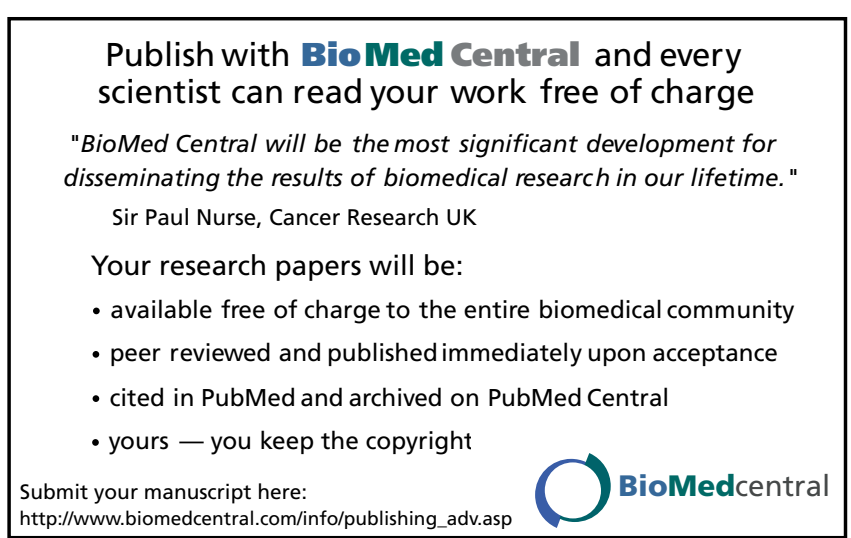

